\title{
ECONOMIA SOLIDÁRIA E GESTÃO SUSTENTÁVEL DA PESCA E AQUICULTURA: UMA ANÁLISE DA ABORDAGEM ECONÔMICO-SOLIDÁRIA EM POLÍTICAS PÚBLICAS DE PESCA E AQUICULTURA NO BRASIL.
}

\author{
Carlos Alberto Pereira de Souto ${ }^{1}$ \\ ${ }^{1}$ Ministério da Pesca e Aquicultura (MPA), Belém, Pará, Brasil, carlos.souto@ mpa.gov.br
}

\begin{abstract}
RESUMO: O trabalho tem por objeto de estudo a relação entre a Gestão Sustentável da Pesca e Aquicultura e a Economia Solidária, a partir da análise da Abordagem Econômico-Solidária em Políticas Públicas de Pesca e Aquicultura no Brasil; com o objetivo de clarear ou revelar as relações presentes, e as possíveis, em gestão sustentável em pesca e aquicultura. A metodologia que guiará tal análise será a da Pesquisa Documentária e Bibliográfica, com inclinação interpretativa, fundamentada na historicidade do Setor de Pesca e Aquicultura e nas pretensões teórico-práticas do Campo da Economia Solidária enquanto paradigma científico alicerçado em engenhosidade política. Os resultados materializam a síntese da reflexão, compreensão e racionalização obtidas na conclusão de que o processo do emprego da Abordagem Econômico-Solidária em Políticas Públicas de Pesca e Aquicultura é uma "construção histórica e paradigmática" que possibilita aos pescadores e aquicultores serem Protagonistas da gestão de Projetos do Ministério da Pesca e Aquicultura (MPA).
\end{abstract}

PALAVRAS-CHAVE: economia solidária, gestão sustentável, pesca e aquicultura, políticas públicas.

\section{SOLIDARY ECONOMY AND SUSTAINABLE MANAGEMENT OF FISHERY AND AQUACULTURE: ECONOMIC SOLIDARY APPROACH IN PUBLIC POLICIES FOR FISHERIES AND AQUACULTURE IN BRAZIL.}

\begin{abstract}
This article studies the relation between Sustainable Management of Fishery and Aquaculture and Solidary Economy, using economic solidary approach in public policies for fisheries and aquaculture in Brazil. It aims to reveal present and possible relations in sustainable management of fisheries and aquaculture. The methodology that will guide this analysis is the interpretive Documentary and Bibliographic Research, grounded in the historicity of Fisheries and Aquaculture Sector and in the pretensions of theoretical and practical field of Solidary Economy as scientific paradigm based in political ability. The results materialize the synthesis of reflection, understanding and rationalization obtained in the conclusion that the process of Solidary Economy Approach employment in Public Policy for Fisheries and Aquaculture is a "paradigmatic and historical construction" which enables fishermen and fish farmers being Protagonists the Ministry of Fisheries and Aquaculture (MFA) Projects.
\end{abstract}

KEY-WORDS: fisheries and aquaculture, public policies, solidary economy, sustainable management.

\section{INTRODUÇÃO}

Neste artigo procuramos contribuir com a compreensão de um novo Paradigma em Políticas Públicas de Pesca e Aquicultura no Brasil: o emprego da Abordagem EconômicoSolidária. Para tanto, primeiramente desenvolvemos uma reflexão sobre o Campo da Economia Solidária; em seguida estabelecemos o Conceito de Abordagem Econômico-Solidária a ser empregado no presente estudo e por fim discutimos a interação da Economia Solidária, na perspectiva da Abordagem EconômicoSolidária, com as Políticas Públicas de Pesca 
e Aquicultura: a Política Nacional de Desenvolvimento Sustentável da Aquicultura e da Pesca; o Plano Amazônia Aquicultura e Pesca - Plano de Desenvolvimento Sustentável e o Projeto dos Centros Integrados da Pesca Artesanal (CIPAR) do Ministério da Pesca e Aquicultura. Para enfim, na Conclusão, consubstanciarmos a síntese da compreensão e racionalização obtidas a partir das abstrações, apreensões e reflexões feitas sobre a Abordagem Econômico-Solidária em Políticas Públicas de Pesca e Aquicultura no país.

\section{MATERIAL E MÉTODOS}

A metodologia que guiará nossa análise será a da Pesquisa Documentária e Bibliográfica, com inclinação interpretativa e exploratória, fundamentada na historicidade do Setor de Pesca e Aquicultura e nas pretensões teórico-práticas do Campo da Economia Solidária enquanto paradigma científico alicerçado em engenhosidade política.

Será realizada uma revisão bibliográfica sobre o Campo da Economia Solidária para elaboração da digressão histórica sobre Economia Solidária; a fim de subsidiar a constituição do Conceito ou Definição de “Abordagem Econômico-Solidária" que guia este estudo. Em seguida, serão analisadas, à luz da abordagem supramencionada, as Políticas Públicas de Pesca e Aquicultura: a Política Nacional de Desenvolvimento
Sustentável da Aquicultura e da Pesca; o Plano Amazônia Aquicultura e Pesca - Plano de Desenvolvimento Sustentável e o Projeto dos Centros Integrados da Pesca Artesanal (CIPAR) do Ministério da Pesca e Aquicultura.

\section{RESULTADOS E DISCUSSÃO}

\section{A ABORDAGEM ECONÔMICO- SOLIDÁRIA}

A compreensão do que denominamos Abordagem Econômico-Solidária exige previamente a compreensão da Economia Solidária (ECOSOL) em seu caráter integral e pleno, abrangendo o conhecimento dos seus antecedentes históricos; origens remotas; (res)surgimento recente; constituição enquanto movimento; delineamento como teoria/doutrina acadêmica e pretensões como sistema alternativo de produção e vida em sociedade. Por essa razão, faz-se a seguir uma digressão histórica sobre Economia Solidária.

Embora o processo histórico de constituição da Economia Solidária não tenha sido linear, por questões didáticas, neste trabalho será apresentado um encadeamento que segue esta lógica de relação na regressão histórica, por ser o mais adequado a compreensão almejada do Segmento.

Para alguns autores os antecedentes históricos da Economia Solidária remontam ações de cooperação ainda na Idade Antiga; para outros, como Robert Putnam (2007, apud 
MIRANDA, 2009) remontam ao final da Idade Média com o surgimento de um grupo de cooperativas na Europa. Dessa forma, os antecedentes históricos da Economia Solidária coincidem com os antecedentes históricos do Movimento Cooperativista, em especial pela correlação de vários princípios balizadores.

Em decorrência, para a maioria dos autores, as origens remotas da Economia Solidária fundam-se nas formas de oposição, luta e resistência dos trabalhadores ao Modo de Produção Capitalista, associados em arranjos cooperativos de produção, crédito e consumo. Sobre o tema nos diz Maud:

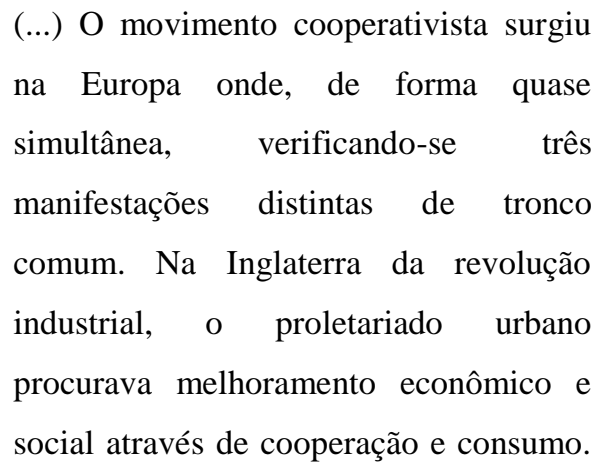
$\mathrm{Na}$ Alemanha - todavia, não industrializada - os camponeses e artesãos buscavam liberar-se da usura mediante as cooperativas de crédito. $\mathrm{Na}$ França, por fim, constituíram-se as cooperativas de produção para oferecer fontes de trabalho de acordo com os postulados revolucionários da época. (MAUD, 2005, apud MIRANDA, 2009, p. 16)

Dado às vinculações históricas no Brasil, quando do ressurgimento do Movimento Cooperativista - também chamado de Novo Cooperativismo, nas décadas de 1960/1970; (res)surgiu também a Economia Solidária, na década de 1980, como proposta agregadora de trabalhadores em arranjos cooperativos, para fazer frente as disfunções e mazelas do Modo de Produção Capitalista e assim dar respostas alternativas a imensa gama de trabalhadores excluídos desse modelo econômico hegemônico e perverso em sua lógica interna. Sobre essa questão é bastante esclarecedor o entendimento de Schiochet:

(...) No Brasil, a Economia Solidária ressurgiu na década de 1980 como uma resposta dos/as trabalhadores/as e comunidades pobres mobilizados socialmente frente a crise social provocada pela estagnação econômica a qual foram submetidas as sociedades periféricas no contexto das contradições da acumulação capitalista. No entanto, a Economia Solidária ganha visibilidade na década seguinte quando se incorpora de forma mais visível às potencialidades transformadoras expressas nas lutas populares. Assim, de uma resposta dos/as trabalhadores/as e comunidades empobrecidas a crise passa a ser reconhecida em seu caráter emancipatório. (SCHIOCHET, 2011, p.443 e 444)

Igualmente esclarecedor sobre o (res)surgimento da ECOSOL é o posicionamento de Benini e Benini (2011) que, ao ressaltarem que muito se fala em "ressurgimento" da Economia Solidária, destacam que isto se deve justamente à retomada dos princípios do cooperativismo, em especial à recuperação da essência que 
provocou a sua elaboração, isto é, a luta contra a exploração do trabalho por meio da auto-organização dos próprios trabalhadores.

Neste contexto, Nascimento (2011) ao tratar da questão, ressalta que o ressurgimento da Economia Solidária ocorreu com força em muitos países. E destaca, em alto relevo, que na verdade a ECOSOL foi reinventada. Para ele o que distingue este "novo cooperativismo" é o retorno aos princípios, o elevado valor atribuído à democracia e à igualdade dentro dos empreendimentos, a insistência na autogestão e o repúdio ao assalariamento.

Portanto, para Nascimento a reinvenção da Economia Solidária carrega em seu bojo "a ressurreição de valores que fazem parte da cultura do movimento operário: solidariedade, autogestão, autonomia, mutualismo, economia moral etc" (NASCIMENTO, 2011, p. 91). Porém agora, mobilizados para o enfrentamento das disfunções, contradições ou mazelas da etapa atual do Modo de Produção Capitalista (Globalização Financeira) representados pela desindustrialização crescente dos países centrais e periféricos; precarização do trabalho; desemprego estrutural em massa; perda da capacidade de luta dos sindicatos em defesa dos direitos dos trabalhadores; exclusão social e outros.

E essa premissa contextual está na base da constituição da Economia Solidária enquanto Movimento Social que, diverso em suas experiências e práticas, apresenta uma identidade própria e comum aos que se identificam nos seus princípios e se reconhecem nos seus valores.

Sobre o assunto, vale a pena trazer a discussão as assertivas de Benini (2011) de que, de certo modo, a Economia Solidária pode ser considerada como um movimento que se situa no contexto do trabalho associado e que também promove, sobretudo, múltiplas combinações e possibilidades. Porém, tal diversidade não é fortuita, sendo o resultado de constantes tentativas de desmercantilização do trabalho, por meio e dentro de novas relações de produção.

Assim, se atualmente a ECOSOL é um Movimento Social específico e altamente politizado, ela teve origem na interação de movimentos sociais diversos no processo histórico de desenvolvimento da questão social no Brasil. Sobre o tema nos diz Schiochet:

(...) a Economia Solidária que surgiu dos movimentos sociais vai se constituindo como um movimento social específico. $\mathrm{E}$, desta forma, vai politizando o próprio campo da Economia Solidária. Isto é, busca dar visibilidade pública a certas identidades coletivas (por exemplo: empreendimento econômico solidário), traduzir as carências destes empreendimentos na forma de direitos, organizar em fóruns, redes, mobilizar e aglutinar os esforços na reivindicação de políticas públicas. Há uma busca pela institucionalização dos direitos próprios 
da Economia Solidária. (...) (SCHIOCHET, 2012, p. 37)

E essa estruturação da ECOSOL enquanto movimento social chamou a atenção da Academia (Universidades) para a Economia Solidária, que passou a ser objeto de estudo, pesquisa e teorização como Campo Interdisciplinar das Ciências Socioeconômicas (Administração; Economia; Sociologia; Pedagogia; Serviço Social e outras); o que possibilitou a constituição de um corpo próprio de princípios, saberes e práticas que elevaram o Campo de Conhecimento da Economia Solidária ao status de Doutrina Acadêmica singular. Sobre o tema assevera Praxedes:

(...) A Economia Solidária tem se
constituído em objeto de análise de
muitos pesquisadores do Brasil e de
outros países, tendo em vista a sua
erupção social nos últimos 20 anos como
expressão da ação pública de diferentes
segmentos sociais. (...) (PRAXEDES,
2012, p. 446)

Cançado et al. (2012) buscaram construir uma alternativa de classificação científica para a Economia Solidária desenvolvendo debate em torno de determinados paradigmas das ciências sociais. Assim, delinearam "os pressupostos segundo os quais a teorização sobre a engenhosidade política da Economia Solidária, em sua experiência brasileira, ganha ares de cientificidade (...)" (CANÇADO et al., 2012, p. 223). E ainda asseveraram:
"Trata-se, portanto, de tentativa de construção de determinada percepção de um possível processo de reflexão sobre a cientificidade da Economia Solidária” (CANÇADO et al., 2012, p. 255).

E esses novos ares de cientificidade atribuída à teoria e/ou doutrina acadêmica da Economia Solidária, acabou por fortalecer as correntes teóricas com aspirações de constituição de um sistema alternativo de produção e vida em sociedade, a partir da ECOSOL. Sobre o tema, filosofa Benini ao tratar do Sistema Orgânico do Trabalho:

(...) o limite da Economia Solidária não
está centrado nas dificuldades de se
"praticar a autogestão no capitalismo",
mas sim, em não entender que autogestão
implica em superar as mediações do
capital, o que significa contrapor as
instituições de dominação capitalista (...)
(BENINI, 2011, p. 87 e 88)

Ainda sobre o assunto, nos diz Fraga (2011) que a Economia Solidária, por meio da autogestão - seu principal fundamento, torna possível a inscrição de um projeto de sociedade na prática cotidiana nas diversas esferas de produção e da reprodução da vida. É a concepção de ECOSOL como força emancipatória dos trabalhadores dos ditames e exploração do Capital.

Neste momento encerra-se a digressão histórica; uma vez que fora cumprida a etapa de retomada dos elementos necessários e suficientes à compreensão ampla e integrada dos vários aspectos da Economia Solidária. E 
o desenvolvimento dessa compreensão abrangente da Economia Solidária, nos permite agora estabelecer uma definição ou conceito para o termo "Abordagem Econômico-Solidária" que seja passível de compreensão e apropriação para aplicação nas análises da Política, Plano e Projeto do Ministério da Pesca e Aquicultura em destaque neste estudo; conforme abaixo apresentado:

Abordagem Econômico-Solidária: é o enfoque que permite o desenvolvimento, direto ou indireto, dos princípios do cooperativismo, solidariedade e autogestão, dos valores da democracia e igualdade dentro dos empreendimentos, dos saberes e práticas do trabalho associado e da sustentabilidade socioambiental na dinâmica da produção e da vida comunitária na perspectiva da Economia Solidária.

Assim, é essa concepção de "Abordagem Econômico-Solidária" que se adotará neste estudo que tem por finalidade analisar a ocorrência, ainda que tácita (implícita) ou incidental (não-intencional), de elementos e/ou reflexos da Economia Solidária nas Políticas, Planos e Projetos do Ministério da Pesca e Aquicultura.

\section{A INTERVENÇÃO PÚBLICA EM PESCA E}

\section{AQUICULTURA}

Segundo a Organização das Nações Unidas para a Agricultura e Alimentação FAO (2006), a evolução histórica da intervenção institucional do Estado no Setor Pesqueiro no Brasil teve início com a atuação da Superintendência de Desenvolvimento da Pesca - SUDEPE, no período de 1955 a 1989, que foi instituída como autarquia federal vinculada ao Ministério da Agricultura - MA. Esse período caracterizou-se por uma política de grandes incentivos fiscais, fortes investimentos no setor e pela institucionalização da pesca como setor autônomo no âmbito da área de agricultura e abastecimento. Contudo, em 1989, em meio a uma crise institucional provocada por questões estruturais internas e conjunturais externas, a SUDEPE teve decretada a sua extinção.

Também em 1989, em razão da mesma conjuntura externa e reorganização de prioridades do Poder Público Federal, foi criado o Instituto Brasileiro do Meio Ambiente e dos Recursos Naturais Renováveis - IBAMA, vinculado ao Ministério do Interior, assumindo as atribuições de fomento e ordenamento da pesca até 1997. A gestão da atividade pesqueira pelo IBAMA teve foco principalmente na conservação e preservação dos recursos pesqueiros, com reduzidas ações de incentivo ao desenvolvimento e fomento da atividade.

Em 1997 é editada a Medida Provisória $\mathrm{N}^{\mathrm{o}} 1549-35$, transformada no ano seguinte na Lei $N^{\circ}$ 9.649, de 27 de maio de 1998, que divide as competências relacionadas às 
atividades pesqueiras entre o Ministério do Meio Ambiente - MMA/IBAMA e o Ministério da Agricultura e Abastecimento MAA. O MMA/IBAMA manteve a competência de ordenamento ambiental pesqueiro, ou seja, a função de preservação, conservação e uso sustentável dos recursos naturais pesqueiros; enquanto o MAA recebeu as atribuições de fomento e desenvolvimento da atividade pesqueira nacional.

O Ministério da Agricultura e Abastecimento - MAA, logo em seguida ao recebimento das novas competências, estruturou o Departamento de Pesca e Aquicultura (DPA) com o intuito de melhor realizar o fomento e desenvolvimento da atividade pesqueira.

A atuação do DPA, conjuntamente com outros agentes/fatores que operavam no segmento, possibilitou uma considerável melhoria da atividade pesqueira no Brasil. Contudo, foi somente com a criação do Ministério da Pesca e Aquicultura que a intervenção pública em pesca e aquicultura atingiu o seu apogeu no Brasil.

\section{O MINISTÉRIO DA PESCA E} AQUICULTURA

Em 2003, já sob o Governo SocialLiberal do Presidente Luis Inácio Lula da Silva, com forte atuação sobre a temática socioeconômica, criou-se uma estrutura mais definitiva para a atuação do Estado no Setor, através da Secretaria Especial de Aquicultura e Pesca (SEAP/PR), criada por meio da Medida Provisória $N^{\circ} 103$ de 28 de maio de 2003 (posteriormente transformada na Lei $\mathrm{n}^{\circ}$ 10.683) e ligada a Presidência da República PR.

A Secretaria Especial de Aquicultura e Pesca - SEAP/PR herdou funções e atribuições do extinto DPA/MAA, acrescidas de novas atribuições referentes à legislação ambiental. Assim, manteve-se a divisão de competências estabelecidas historicamente entre o MMA; o IBAMA e o DPA - este último agora substituído pela SEAP/PR.

Contudo em 2009, com a edição da Lei ${ }^{\circ}$ 11.958, de 26 de junho de 2009, a Secretaria Especial de Aquicultura e Pesca da Presidência da República - SEAP/PR, existente desde 2003, foi transformada no Ministério da Pesca e Aquicultura - MPA. O MPA tem por finalidade e competência institucional promover e desenvolver Políticas Públicas voltadas para o ordenamento, gestão e fomento dos setores pesqueiro e aquícola, mantendo o compromisso com a sustentabilidade ambiental no uso dos recursos pesqueiros no país.

\section{FORMAS DE INTERVENÇÃO PÚBLICA}

Conforme a contextualização histórica acima apresentada, não é de hoje que o Poder Público intervém em pesca e aquicultura: planejando, regulando, gerenciando e fomentando o Segmento da Pesca e Aquicultura no país. No entanto, somente 
com a criação do Ministério da Pesca e Aquicultura o setor foi adequadamente dimensionado e devidamente alocado dentro das prioridades governamentais, alcançando posição de destaque no planejamento da intervenção estatal e na agenda governamental, com o intuito de atingir a plenitude do potencial pesqueiro e aquícola nacional.

Assim, é com tal finalidade que o Poder Público, através do MPA, intervém qualificadamente no Setor de Pesca e Aquicultura; desenvolvendo Políticas Públicas, elaborando Planos e implementando Projetos específicos junto aos atores do Segmento Pesqueiro e Aquícola Nacional; dentre os quais merecem especial destaque neste estudo: a Política Nacional de Desenvolvimento Sustentável da Aquicultura e da Pesca; o Plano Amazônia Aquicultura e Pesca - Plano de Desenvolvimento Sustentável e o Projeto dos Centros Integrados da Pesca Artesanal (CIPAR), pelo valor estruturante que estes promovem nas atividades pesqueiras e aquícolas nacionais, à luz da Abordagem Econômico-Solidária.

\section{ANALISANDO A INTERVENÇÃO PÚBLICA À LUZ DA ABORDAGEM ECONÔMICO-SOLIDÁRIA}

\section{Analisando a Política}

$\mathrm{Na}$ perspectiva da Abordagem Econômico-Solidária, existe certamente uma interação entre a Economia Solidária e a
Política Nacional de Desenvolvimento Sustentável da Aquicultura e da Pesca. E a pedra fundamental dessa interação foi assentada ainda na Lei $\mathrm{n}^{\circ} 11.958$, de 28 de junho de 2009 (que dispõe sobre a transformação da SEAP/PR em MPA, e da outras providências), que incluiu entre as competências e atribuições do MPA, através das Superintendências Federais de Pesca e Aquicultura nos Estados, o fomento e promoção do "cooperativismo e associativismo de pescadores e aquicultores" (Art. 9', Inc. V), e de suas comunidades, visando ao desenvolvimento socioeconômico, cultural e profissional em bases comunitária e local.

Dessa forma, nesse ponto há o entrelaçamento entre a Lei $n^{\circ} 11.958$, de 28 de junho de 2009 (que dispõe sobre a transformação da SEAP/PR em MPA, e da outras providências) e a Lei $n^{\circ} 11.959$, de 29 de junho de 2009 (que institui a Política Nacional de Desenvolvimento Sustentável da Aquicultura e da Pesca e dá outras providências); uma vez que a competência e atribuição de fomentar e promover "o cooperativismo e associativismo de pescadores e aquicultores" (Art. $9^{\circ}$, Inc. V) prevista na primeira Lei; se alinha perfeitamente aos objetivos últimos da segunda Lei, a Política Nacional de Desenvolvimento Sustentável da Aquicultura e da Pesca, que é, dentre outros, de promover: “o desenvolvimento sustentável da pesca e 
aquicultura como fonte de alimento, emprego, renda e lazer, com a otimização dos benefícios econômicos decorrentes" (Art. 1º, Inc. I) e "o desenvolvimento socioeconômico, cultural e profissional dos que exercem a atividade pesqueira, bem como de suas comunidades" (Art. $1^{\circ}$, Inc. IV). Abrindo assim, um enorme espaço para a atuação da Economia Solidária no Segmento da Pesca e Aquicultura.

Para além das questões técnicas registradas na Política Nacional de Desenvolvimento Sustentável da Aquicultura e da Pesca (Lei $n^{\circ} 11.959$, de 29 de junho de 2009), é notória a adequação dos ditames imperativos de seus principais Artigos, tais como: o Art. $3^{\circ}$ (da sustentabilidade do uso dos recursos pesqueiros); o Art. $7^{\circ}$ (formas de efetivação do desenvolvimento sustentável da atividade pesqueira) e o Art. 28 (modos de organização da comercialização dos produtos pesqueiros dos associados das colônias de pescadores) aos pressupostos, princípios e valores da Economia Solidária; conforme abaixo se demonstrará.

O Art. $3^{\circ}$ da Lei $n^{\circ} 11.959$, de 29 de junho de 2009, em síntese, assevera que na regulamentação da Política Nacional de Desenvolvimento Sustentável da Atividade Pesqueira compete ao Poder Público: “conciliar o equilíbrio entre o princípio da sustentabilidade dos recursos pesqueiros e a obtenção de melhores resultados econômicos e sociais" (Caput), devendo ainda "considerar no ordenamento pesqueiro as peculiaridades e as necessidades dos pescadores artesanais, de subsistência e da aquicultura familiar, visando a garantir sua permanência e sua continuidade" $\left(\S 1^{\circ}\right)$; o que cristalinamente se compatibiliza com os preceitos da Abordagem Econômico-Solidária anteriormente apresentada, em especial os da sustentabilidade ambiental e social dos pescadores, aquicultores e de suas comunidades.

Por sua vez, o Art. $7^{\circ}$ da Lei $n^{\circ} 11.959$, de 29 de junho de 2009, estabelece as formas de efetivação do desenvolvimento sustentável da atividade pesqueira, dentre as quais destacamos: "a participação social” (Inc. III); pela plena adequação a Abordagem Econômico-Solidária que prima pela participação social proativa, democrática, igualitária e solidária.

Por último, o Art. 28 da Lei no 11.959, de 29 de junho de 2009, que trata dos modos de organização da comercialização dos produtos pesqueiros dos associados das colônias de pescadores, estabelece que "a comercialização dos produtos pesqueiros poderão se dar diretamente pelas colônias ou por intermédio de cooperativas ou outras entidades constituídas especificamente para esse fim" (Corpo); o que também se compatibiliza com os preceitos da Abordagem EconômicoSolidária, que tem no associativismo e cooperativismo dois de seus principais fundamentos. 
Portanto, vale esclarecer que, no que concerne a interação entre a Economia Solidária e a Política Nacional de Desenvolvimento Sustentável da Aquicultura e da Pesca, o critério técnico-científico que se faz necessário ao exame é de compatibilidade e adequação; posto que não se trata de uma Política Nacional específica de Economia Solidária. Entretanto, constitui-se numa Política Nacional que permite a inserção do Campo da ECOSOL, e de suas práticas, pela elevada aproximação de suas disposições normativas com os preceitos da Economia Solidária, na perspectiva da Abordagem Econômico-Solidária que guia este estudo.

\section{Analisando o Plano}

Há elementos e/ou reflexos de Economia Solidária, na ótica da Abordagem EconômicoSolidária, no Plano Amazônia Aquicultura e Pesca - Plano de Desenvolvimento Sustentável, do Ministério da Pesca e Aquicultura, para o período: 2009 - 2015 .

O Plano Amazônia Aquicultura e Pesca Plano de Desenvolvimento Sustentável é um Plano Setorial elaborado pelo Ministério da Pesca e Aquicultura, com a participação do setor produtivo e da sociedade civil organizada, para as populações que vivem na região e que segue as diretrizes do Plano Amazônia Sustentável (PAS), sendo que sua gestão se dá por meio do comitê gestor instituído no âmbito da comissão gestora do PAS.
Embora na configuração do Plano os elementos e/ou reflexos de Economia Solidária se apresentem integrando objetivos, diretrizes, ações e metas; tal integração se deve a introdução da doutrina de ECOSOL em momentos anteriores, que remontam há alguns anos, e cujo marco formal é a edição do Caderno: "Economia Solidária" - Série Formação e Valorização do Pescador, para a realização do Curso sobre Economia Solidária, em 2007, para pescadores artesanais e comunidades, quando do reordenamento da pesca da lagosta. Sendo as práticas da Economia Solidária institucionalmente apropriadas e fomentadas pelo MPA no Projeto "Centros Integrados da Pesca Artesanal (CIPAR) implantados nos Estados e que é objeto de análise no tópico a seguir.

Portanto, o critério técnico-científico que se emprega ao exame aqui, também é o de compatibilidade e adequação das disposições regulamentares do Plano Amazônia Aquicultura e Pesca - Plano de Desenvolvimento Sustentável às premissas e preceitos da Economia Solidária.

Desse modo, os objetivos do Plano de “apoiar o desenvolvimento sustentável e a redução das desigualdades sociais, econômicas e territoriais de maneira alternativa às matrizes produtivas vigentes" são perfeitamente adequados, não só aos preceitos da Economia Solidária, mas também aos próprios objetivos da Economia Solidária, 
à luz da Abordagem Econômico-Solidária descrita neste trabalho.

Igualmente, as diretrizes do Plano de “promover o desenvolvimento com sustentabilidade e inclusão social; apoio à organização do setor e gestão pesqueira e aquícola compartilhada e integrada ao desenvolvimento territorial", nos termos nele especificados, são perfeitamente compatíveis com as premissas e preceitos da Economia Solidária; uma vez que visam à melhoria da renda e da qualidade de vida dessas populações (pescadores, pequenos e médios aquicultores e comunidades tradicionais) levando em conta sua diversidade ambiental, econômica, social, cultural e política na promoção, de forma participativa, do planejamento e da organização do Setor Pesqueiro, tendo no associativismo e cooperativismo importantes instrumentos para tal.

No que se refere às ações do Plano; merece especial destaque a ação: "fortalecimento do associativismo e do cooperativismo", pela absoluta evidência de adequação de tal ação as premissas, valores, preceitos e aspirações da Economia Solidária. É, pois, a ação na qual a Abordagem Econômico-Solidária encontra maior abrigo para o seu desenvolvimento gradual e crescente em Programas e Projetos promovidos pelo MPA.

Quanto às metas estabelecidas no Plano; a meta de "incentivo ao associativismo e ao cooperativismo", através de 100 (cem) organizações apoiadas até 2015, destaca-se sobre as demais pela perfeita compatibilidade com as premissas e preceitos da Economia Solidária; além de vir ao encontro dos anseios do Movimento de ECOSOL, por tratar da questão da organização social visando, dentre outros, ao desenvolvimento da qualidade de vida, a melhoria da renda, ao fortalecimento da economia familiar e a melhoria do acesso às políticas públicas disponíveis.

Assim sendo, a Abordagem EconômicoSolidária está compreendida no Plano Amazônia Aquicultura e Pesca - Plano de Desenvolvimento Sustentável, mais precisamente nos elementos e/ou reflexos de Economia Solidária anteriormente mencionados; que servem de premissas ou pressupostos para a adoção, manutenção e desenvolvimento da Abordagem EconômicoSolidária em Programas e Projetos promovidos pelo MPA, tal qual o Projeto: Centros Integrados da Pesca Artesanal (CIPAR), a seguir analisado em detalhes.

\section{Analisando o Projeto}

Primeiramente, vale destacar que é evidente o emprego da Abordagem Econômico-Solidária no Projeto: Centros Integrados da Pesca Artesanal (CIPAR) do Ministério da Pesca e Aquicultura. Em especial, porque o Projeto CIPAR tem na forma de gestão: a autogestão dos 
empreendimentos, um dos principais, senão o principal, fundamento da Economia Solidária.

Além disso, segundo o próprio MPA (2009b), a prioridade consiste no desenvolvimento dos elos da cadeia produtiva da pesca artesanal e aquicultura familiar, com base na autogestão dos empreendimentos e no fomento do cooperativismo e do associativismo fundamentados nos princípios da Economia Solidária.

Em resumo, os Centros Integrados da Pesca Artesanal (CIPAR) são infraestruturas de pequeno e médio porte, destinadas a apoiar as atividades de movimentação, beneficiamento, armazenamento e comercialização de pescado que articulam, ou buscam articular, regionalmente as Políticas Públicas do MPA para a pesca artesanal, focando e concentrando investimentos na infraestrutura da Cadeia Produtiva; ensino e qualificação profissional; apoio à autogestão dos empreendimentos; gestão compartilhada e ordenamento pesqueiro local.

Vale ressaltar que as ações e investimentos podem ser diferenciados em cada CIPAR, inclusive no mesmo Estado, a depender das características e condições locais, bem como das demandas específicas dos atores locais envolvidos; que são definidas através da aplicação de metodologias participativas junto às comunidades.

Dessa forma o Projeto CIPAR pode incluir, com relação à infraestrutura da Cadeia
Produtiva do Pescado, que vai da produção até a comercialização, uma variedade de ações e investimentos nos campos da: produção e distribuição de insumos (óleo diesel; fábrica de gelo; caminhões frigoríficos; estações de beneficiamento; kit feira do peixe; etc.); embarque e desembarque (rampas; trapiches; ancoradouros e outros); beneficiamento e conservação do pescado (estruturas de recepção, lavagem e processamento; túnel de congelamento; câmaras frias; etc.); manutenção e reparos navais (galpão de carpintaria; equipamentos para carpintaria; máquinas para reparos mecânicos e elétricos; etc.).

Quanto ao apoio à autogestão dos empreendimentos, que se faz de modo continuado, o Projeto CIPAR pode incluir ações e investimentos variados, tais como: cursos de Economia Solidária, associativos e cooperativismo; elaboração de planos de negócios; planejamento da comercialização; acompanhamento técnico por incubadora de cooperativas e outros.

Por sua vez, no que tange a formação, capacitação e qualificação profissional, o Projeto CIPAR pode incluir ações e investimentos em: salas de aula e de reuniões; inclusão digital (Projeto Telecentros Maré); projetos de alfabetização de jovens e adultos (Projeto Pescando Letras); e cursos diversos de qualificação profissional (educação profissional; cursos de carpintaria e cursos técnicos). 
Já quanto aos mecanismos de apoio ao ordenamento pesqueiro local e gestão compartilhada, o Projeto CIPAR pode incluir ações e investimentos em: parcerias com o Ministério do Meio Ambiente - MMA, Instituto Chico Mendes da Biodiversidade ICMBIO e Instituto Brasileiro do Meio Ambiente e dos Recursos Naturais Renováveis - IBAMA; apoio a projetos de educação ambiental; apoio ao monitoramento dos recursos pesqueiros (agentes ambientais voluntários e outros); elaboração de projetos de gestão compartilhada; e constituição ou fortalecimento de fóruns de gestão compartilhada dos recursos pesqueiros.

Além do mais, na escolha das áreas para a implementação do Projeto CIPAR nos Estados, são consideradas as demandas estaduais, territoriais e critérios que valorizem a relevância da pesca artesanal nos Estados (o número de pescadores no Registro Geral da Atividade Pesqueira - RGP do MPA; produção de pescado; existência de outros empreendimentos do MPA; etc.); a fim de subsidiar a elaboração de um Projeto que contemple às infraestruturas necessárias; formação e capacitação; apoio à gestão de empreendimentos; e apoio ao ordenamento local e gestão compartilhada dos recursos pesqueiros. Para então realizar a visita técnica para a apresentação e discussão da proposta de instalação de um CIPAR e levantamento de demandas preliminares, com emprego de metodologias participativas, para inclusão ou adequação de demanda visando garantir a legitimação do Projeto pela comunidade e promover os esclarecimentos necessários para que a decisão comunitária seja pela implantação do CIPAR.

Contudo, é fundamentalmente a proposta de forma de gestão do Projeto CIPAR: $a$ autogestão - gestão pelos próprios integrantes das comunidades pesqueiras, que o insere na Abordagem Econômico-Solidária em Políticas Públicas em Pesca e Aquicultura. Outros princípios da Economia Solidária também são incorporados ao Projeto CIPAR, como: o associativismo; cooperativismo; a participação democrática; e a sustentabilidade ambiental e social visando à promoção, geração e distribuição de oportunidades de trabalho e renda àqueles que participam da cadeia produtiva do pescado; para garantir a melhoria de suas qualidades de vida.

Portanto, a despeito de eventuais falhas temporárias e/ou dificuldades de execução local, $o$ assessoramento continuado $e$ a capacitação deverão fortalecer as bases da Autogestão, a mola mestra propulsora do Projeto CIPAR, e assim garantir a continuidade do principal Projeto da Abordagem Econômico-Solidária no Ministério da Pesca e Aquicultura.

\section{CONCLUSÃO}

O processo do emprego da Abordagem Econômico-Solidária em Políticas Públicas 
de Pesca e Aquicultura é uma construção histórica, ainda que contemporânea ou recente, e vai da introdução teórico-conceitual da Economia Solidária no Setor até a práxis ou experiência concreta em ECOSOL no Segmento de Pesca e Aquicultura, com o Projeto CIPAR.

A Abordagem Econômico-Solidária é um novo Paradigma em Políticas Públicas e, superado seu momento de construção, estamos entrando em uma nova fase de seu desenvolvimento, a fase expansionista, adequada ao seu caráter de tema transversal e multifacetado em Políticas Públicas no Brasil, em franca absorção pela agenda dos Estados e Municípios por ação do Movimento de ECOSOL.

Assim, dando fluência a fase expansionista da ECOSOL, o desenvolvimento do Projeto CIPAR possibilita a Espacialização da Abordagem Econômico-Solidária; pois, só na Amazônia, está prevista a instalação de 45 CIPAR's até 2015, segundo o Plano Amazônia Aquicultura e Pesca - Plano de Desenvolvimento Sustentável.

Portanto, conclui-se que a Abordagem Econômico-Solidária desponta entre as Abordagens em Políticas Públicas de Pesca e Aquicultura, em especial e no que lhe é particular, pela concepção de desenvolvimento alicerçado na Construção Societária, com caráter transformador, por possibilitar aos pescadores e aquicultores serem Protagonistas da gestão $e$ desenvolvimento sustentável de Projetos de Pesca e Aquicultura promovidos pelo MPA e não meramente coadjuvantes passivos da gestão convencional dos mesmos, como acontecem em outras Abordagens em Políticas Públicas.

\section{REFERÊNCIAS}

BENINI, E. A. Sistema orgânico do trabalho: uma perspectiva de trabalho associado a partir das práxis de economia solidária. In: BENINI, E. A.; SARDÁ DE FARIA, M.; NOVAES, H. T.; DAGnino, R. (Org.) Gestão Pública e Sociedade: Fundamentos e políticas públicas de economia solidária. São Paulo: Outras Expressões, 2011, v.1, p. 71 - 90.

BENINI, E. A.; BENINI, E. G. Políticas públicas e economia solidária: elementos para a agenda de uma nova rede de proteção social. In: BENINI, E.; SARDÁ DE FARIA, M.; NOVAES, H. T.; DAGNINO, R. (Org.) Gestão Pública e Sociedade: Fundamentos e políticas públicas de economia solidária. São Paulo: Outras Expressões, 2011, v.1, p. 453 472.

CANÇADO, A. C.; OLIVEIRA, A.; PACÍFICO FILHO, M. Economia solidária: uma representação científica por meio de três paradigmas das ciências sociais. In: BENINI, E.; SARDÁ DE FARIA, M.; NOVAES, H. T.; DAGnino, R. (Org.) Gestão Pública e Sociedade: Fundamentos e políticas públicas 
de economia solidária. São Paulo: Outras Expressões, 2012, v.2, p. 223 - 258.

FAO - Organização das Nações Unidas para a Agricultura e Alimentação. Fortalecimento institucional da secretaria especial de aquicultura e pesca- SEAP/PR. Projeto FAO TCP/BRA 3001. Brasil, 2006.

Disponível em: <http://www.mpa.gov.br/images/Docs/Publici dade/FAO_Final_extrato_discussao.pdf>. Acesso em: 20 jun. 2012.

FRAGA, L. S. Autogestão e tecnologia social: utopia e engajamento. In: BENINI, E.; SARDÁ DE FARIA, M.; NOVAES, H. T.; DAGnino, R. (Org.) Gestão Pública e Sociedade: Fundamentos e políticas públicas de economia solidária. São Paulo: Outras Expressões, 2011, v.1, p. 101 - 124.

MIRANDA, S. A. A. Análise de hipóteses jurídicas de parcerias entre o governo federal e as instituições voltadas ao apoio da economia solidária. Cadernos Brasil Local: Desenvolvimento e Economia Solidária, $\mathrm{n}^{\circ}$ 2, p.15 - 37, 2009.

BRASIL. Lei n. 11.959, de 29 de junho de 2009, Dispõe sobre a política nacional de desenvolvimento sustentável da aquicultura e da pesca e da outras providências. Diário Oficial da República Federativa do Brasil, Brasília, DF, n. 122, p.1 - 3, 30 jun. 2009. Seção 1.
MPA - Ministério da Pesca e Aquicultura. Amazônia Aquicultura e Pesca - Plano de Desenvolvimento Sustentável. Brasília: MPA, 2009b. 15 p

\section{Projeto CIPAR - Centros}

Integrados da Pesca Artesanal. Brasília: MPA, 2009c. 2 p

NASCIMENTO, C. A autogestão e o "novo cooperativismo". In: BENINI, E.; SARDÁ DE FARIA, M.; NOVAES, H. T.; DAGNINO, R. (Org.) Gestão Pública e Sociedade: Fundamentos e políticas públicas de economia solidária. São Paulo: Outras Expressões, 2011, v.1, p. 91 - 99.

PRAXEDES, S. F. Políticas públicas de economia solidária: novas práticas, novas metodologias. In: BENINI, E.; SARDÁ DE FARIA, M.; NOVAES, H. T.; DAGNINO, R. (Org.) Gestão Pública e Sociedade: Fundamentos e políticas públicas de economia solidária. São Paulo: Outras Expressões, 2012, v.2, p. 445 - 456.

SCHIOCHET, V. Políticas públicas de economia solidária: breve trajetória e desafios. In: BENINI, E; SARDÁ DE FARIA, M.; NOVAES, H. T.; DAGNINO, R. (Org.) Gestão Pública e Sociedade: Fundamentos e políticas públicas de economia solidária. São Paulo: Outras Expressões, 2011, v.1, p. 443 - 452.

SCHIOCHET, V. Da democracia à autogestão: economia solidária no Brasil. In: 
BENINI, E.; SARDÁ DE FARIA, M.; NOVAES, H. T.; DAGNINO, R. (Org.) Gestão Pública e Sociedade: Fundamentos e políticas públicas de economia solidária. São Paulo: Outras Expressões, 2012, v.2, p. 17 44. 